\title{
¿Tontas y Locas?: género y movimientos sociales en la ficción televisiva sobre la transición española ${ }^{1}$
}

\author{
Carlota Coronado RuIz \\ Universidad Complutense de Madrid \\ carlotacoronado@gmail.com \\ Elena GALÁN FAJARDO \\ Universidad Carlos III de Madrid \\ egalan@hum.uc3m.es
}

Recibido: 6 de septiembre de 2015

Aceptado: 18 de noviembre de 2015

\section{Resumen}

En la última década se ha puesto de moda la ficción histórica televisiva y en España se han llevado a la pequeña pantalla historias ambientadas en el pasado más reciente como la dictadura franquista o la Transición. En series como Cuéntame cómo pasó o La chica de ayer se representa la sociedad española de entonces, así como los movimientos políticos y sociales que surgieron en aquellos años, entre ellos, el feminismo. A través de este estudio se analiza la imagen que estas series han transmitido sobre los movimientos feministas y sobre la mujer en la Transición.

Palabras clave: Mujer; feminismo; movimientos sociales; Transición Española; Televisión; Ficción histórica televisiva.

\section{Dumb and crazy?: Gender and social movements in TV fiction regarding spanish transition to democracy}

\begin{abstract}
In the last decade, Tv's historical fiction has become a trend and Spain has contributed with stories set in the country's most recent past, like Franco's regime or the transition to democracy. In TV shows like Cuentame cómo pasó or La chica de ayer, spanish society is portrayed, including political and social movements that were born in that era, among them, feminism. Though this article, the image portrayed by these series of the feminist movement and women during the transition to democracy, are analyzed.
\end{abstract}

Keywords: Female; Feminism; Social Movements; Spanish Transition to democracy; Television; TV's Historical Fiction.

\section{Referencia normalizada}

Coronado Ruiz, C. y Galán Fajardo, E. (2015). ¿Tontas y locas?: género y movimientos sociales en la ficción televisiva sobre la transición española. Historia y Comunicación Social. Vol 20, número 2, páginas 327-343.

Sumario: 1.Introducción. 2. El movimiento feminista en España durante la Transición. 3. Género y movimientos sociales durante la Transición: su representación en la ficción televisiva. 3.1. Hipótesis y objetivos de la investigación. 4. "Yo también soy adúltera": feminismo, mujer y sexualidad en la Transición. 4.1. "En mi cama mando yo": ¿destape o libertad sexual?. 4.2. "Nosotras parimos, nosotras decidimos". Mujer y movimientos políticos. 5. Conclusiones. 6. Referencias bibliográficas. 


\section{Introducción}

Cuando en una serie de ficción histórica de producción española aparece una feminista, suele estar presentada como una loca o una histérica, uno de los estereotipos más reiterados en la representación audiovisual de este colectivo. Lejos de ser mujeres que luchan por una mejora de sus derechos y por una igualdad de facto, estos personajes - por lo general secundarios -, se limitan a gritar las consignas más conocidas del movimiento feminista en España y a despreciar a cualquier hombre que se les ponga por delante.

La repetición de estereotipos negativos sobre un determinado colectivo o grupo social en el cine o la televisión tiene una gran incidencia en la mentalidad de una sociedad, debido a la capacidad de estos medios de comunicación de masas para perpetuar ideas y estereotipos entre el público. La cantidad de tiempo de exposición a un medio como la televisión y la importancia que se le da en nuestras vidas hace que la influencia de ésta sea enorme. Desde pequeños, los telespectadores imitan comportamientos, siguen modelos de conducta y aprender a ser quiénes son, en parte, a través de los medios audiovisuales.

Uno de los formatos televisivos que más influyen en la creación de estereotipos de género y la consolidación de una determinada mentalidad hacia las relaciones entre hombres y mujeres, es la ficción televisiva. En las series de producción española se repiten una serie de tópicos no sólo relacionados con el género, sino también con otras señas de identidad como las regionales o nacionales, o bien relacionadas con la profesión o la edad. Desde el "abuelo cebolleta" al mecánico manchado de grasa y el albañil que echa piropos a toda mujer que pase por su lado.

Los estereotipos femeninos más repetidos en la ficción televisiva española han sido objeto de análisis en algunos estudios - como se señalará más adelante.-, pero en ninguno de ellos se han centrado en la representación de la mujer y de los movimientos feministas en la ficción histórica española ambientada en la Transición. Sobre series como Cuéntame cómo pasó o 23F. El día más difícil del rey, existe un mayor número de artículos e investigaciones ${ }^{2}$, pero su enfoque es bastante general, por lo que no desarrollan en profundidad el tema de los movimientos sociales protagonizados por las mujeres en estos años ${ }^{3}$.

En este artículo, sin embargo, se realiza un análisis de la representación de la mujer y el movimiento feminista del tardofranquismo y los primeros años de la democracia en España, centrándose especialmente en dos producciones televisivas: Cuéntame cómo pasó y La chica de ayer. Para encuadrar mejor estos aspectos, se llevarán a cabo dos breves recorridos: un histórico, a través del desarrollo del feminismo en la Transición; y otro televisivo, que supondrá un repaso por la producción televisiva ambientada en estos años de la Historia de España. Ambos son necesarios para comprender mejor cómo ha sido la representación televisiva de un movimiento social como el feminismo, así como de las integrantes de éste. 


\section{El movimiento feminista en España durante la Transición}

La mayoría de los estudios sitúan el arranque del movimiento feminista en España entre 1965-1975; es decir, en el último período del franquismo o "tardo-franquismo" (Larumbe, 2002:139). Esto no quiere decir que durante los primeros años de la década la mujer no luchase de forma activa contra la dictadura, pero canalizaba sus reivindicaciones a través de movimientos existentes hasta que, en los años setenta, comenzaron a surgir formas de organización propia e independiente, sobre todo gracias a la presencia de la mujer en el entorno laboral.

En ese período comenzaron a gestarse los primeros movimientos feministas que luchaban por la liberación de la mujer. Obras como las de Lidia Falcón - Los derechos civiles de la mujer y Los derechos laborales de la mujer, de 1963 y 1964, respectivamente -, exponían temas que nunca antes se habían tratado desde el ámbito del derecho.

En cuanto a la producción teórica, en 1966 se tradujeron al catalán las dos obras representativas de las dos autoras feministas con más prestigio a nivel internacional: La mística de la feminidad de Betty Friedman y El segundo sexo, de Simone de Beauvoir. Estas obras fomentaron la introducción de nuevas ideas en una España donde la palabra feminismo era todavía un término repudiado y objeto de mofa y burla (Larumbe, 2006:152).

Las primeras asociaciones de mujeres que, con carácter legal, se constituyeron bajo el franquismo, estuvieron relacionadas directamente con el ámbito universitario y el profesional. Destacó especialmente el MDM (Movimiento Democrático de las Mujeres) de Madrid, constituido por militantes comunistas y otras afiliadas, que consiguió irse asentando en distintas ciudades de la geografía española.

La muerte del general Franco y los años de la transición democrática hasta la promulgación en 1978 de la Constitución Española, fueron fundamentales en la recuperación de los derechos civiles y políticos de la ciudadanía, y en especial los de las mujeres. Ello generó el marco político propicio para el nacimiento del movimiento feminista.

La Transición es un período histórico aún reciente, por lo que sigue generando controversia y debate. Sin embargo, son poco profusos aún los estudios que se han planteado el análisis de las contribuciones que los movimientos feministas y de mujeres al asentamiento de la democracia en España, a pesar de la existencia de la rigurosa bibliografía al respecto que ha ido surgiendo en los últimos años.

Frente al protagonismo masculino, las mujeres aparecieron en un papel secundario que, según algunas investigaciones (de Diego, 2008), no se ha correspondido con la realidad y parece que la transición se ha erigido como un logro exclusivamente masculino. No obstante, hubo importantes protagonistas como Dolores Ibárrubi, Victoria Kent, Mercedes Fórmica, Carmen Llorca, Belén Ladánburu, etc. que tuvieron que afrontar discriminaciones legales y enfrentarse con una sociedad reaccionaria que las excluía de la vida pública. Y, aún así, dieron pasos muy importantes para 
conseguir la igualdad. La revolución femenina no hubiese sido posible sin la movilización de muchas de ellas. Su asociación y planificación de líneas conjuntas de protestas y reclamación de derechos comenzaron a visibilizar al resto de la sociedad de que había llegado la hora del cambio.

A pesar de que los partidos políticos surgidos tras la dictadura eran conscientes de que, en la nueva etapa que comenzaba, las mujeres tenían que ser ciudadanas de pleno derecho, ello no significaba que sus demandas tuvieran satisfacción inmediata. Hasta en el seno de los partidos más progresistas, los asuntos relacionados con la igualdad de la mujer siempre aparecían en un segundo plano, a pesar (y gracias) a la insistencia de muchas de ellas. A modo de ejemplo, en las elecciones de 15 de junio de 1977, sólo un 13\% de los candidatos al Congreso fueron mujeres, porcentaje que se reducía al 4\% en el Senado (de Diego, 2008: 21).

El año 1975, declarado por las Naciones Unidas como Año Internacional de la Mujer, fomentó la celebración de centenares de actos y campañas en todo el mundo. En España, la organización de los grupos de encuentro fue encargada oficialmente a la Sección Femenina, pero un grupo de mujeres progresistas, aprovechando la opción que daba la convocatoria a presentarse como organizaciones no gubernamentales, enviaron sus propuestas con la intención de mostrar una óptica distinta a la oficial. Ese mismo año se creó el Seminario Colectivo Feminista de Madrid, alrededor del despacho de la abogada Cristina Alberdi. Y, posteriormente, el Colectivo Feminista de Barcelona, impulsado por Lidia Falcón.

Las Jornadas de Liberación de la Mujer en Madrid, en 1975 fueron, para muchos autores, el punto de partida del renacer del feminismo en España. Estuvieron enmarcadas además por otras dos jornadas: las Jornades Catalanes de la Dona, en mayo de 1976 y las II Jornadas Estatales de la Mujer, en 1979, en Granada. Estos tres encuentros, en Barcelona, Madrid y Granada, fueron claves para la multiplicación de los grupos y asociaciones de mujeres.

Dos fueron los rasgos característicos del movimiento feminista: por un lado, la fragmentación y, por otro, la variedad de enfoques teóricos. Pero enseguida surgió la confrontación entre las partidarias de la doble militancia (Nash, 2009): las que creían en la lucha feminista dentro de los partidos políticos, compaginando los dos ámbitos para conseguir sus objetivos; $y$ las adeptas a una única y exclusiva militancia feminista, que rechazaban el mundo político por asentarse en principios patriarcales y para lo que propugnaban una línea política independiente. No obstante, todas ellas acordaron denunciar el desinterés de los partidos políticos por los derechos y la liberación de las mujeres.

Esa fue la antesala de la plena igualdad de género que se vería reflejada en la Ley de Reforma del Código Civil de 2 de Mayo de 1975, la más amplia con respecto a los derechos y capacidad de la mujer casada, y que modificó 57 artículos relativos a dicha capacidad. Se eliminaron los preceptos que imponían la licencia marital para los actos y contratos de la mujer casada, refiriéndose a ambos cónyuges. Desapareció a su vez la fórmula de obediencia y sumisión de la mujer respecto al marido. 
Algunas reivindicaciones comunes a la mayor parte de las organizaciones fueron: la consecución de la democracia y el restablecimiento de las libertades; alcanzar una serie de modificaciones legales aún por conseguir; la construcción y proyección de una imagen positiva de la mujer o conseguir la igualdad en el ámbito laboral, específicamente en el acceso a grupos de responsabilidad.

Por otro lado, otras campañas llevadas a cabo por los movimientos de mujeres tuvieron como protagonista la venta y publicidad de anticonceptivos, el derecho a la educación y a la libertad en la decisión del propio cuerpo. No obstante, muchas de estas campañas - como las de educación sexual y control de la natalidad - tuvieron que operar en la clandestinidad, hasta el 7 de octubre de 1978, fecha en que se despenalizaron los anticonceptivos. Uno de los lemas más repetidos fue "lo personal es político", en referencia a los derechos de las mujeres a sus propios cuerpos.

Los Pactos de la Moncloa en Octubre de 1977 incluyeron acuerdos sobre la despenalización de la propaganda y difusión de los anticonceptivos. Un año más tarde, en octubre de 1978, el gobierno de UCD aprobó la despenalización de los anticonceptivos (Nash, citado en Ortega López, 2009: 85). La Constitución de 1978 dio un importante paso en el reconocimiento y libertades de las mujeres españolas y un giro radical en la igualdad de los sexos.

\section{Género y movimientos sociales durante la Transición: su representación en la ficción televisiva}

Uno de los cambios más importantes en la óptica de análisis de distintas disciplinas académicas, desde los años ochenta, fue la introducción del "género" como categoría. En ese sentido, los estudios sobre cultura popular fueron el objeto de una gran parte de análisis feministas, pues además permitieron una visión en profundidad y desde nuevos enfoques en la agenda social y política.

El concepto "género", impulsado por el feminismo académico anglosajón en los años setenta, abrió un amplio campo de estudio acerca de cómo las identidades y las relaciones entre hombres y mujeres eran construidas. También sirvió para analizar qué desigualdades de poder se derivaban de esa construcción socio-cultural. Esa relación entre género y ámbito político, social y cultural fue denominado como "tecnología de género" (De laurentis, 1989: 1-30).Estas nuevas categorías de análisis no sólo abrieron nuevas posibilidades a la lucha feminista, sino también a los incipientes estudios sobre las masculinidades, que comenzaron a poner su atención en la construcción social de la identidad masculina y a cuestionar los modelos hegemónicos.

En los últimos treinta años, los términos "género", "representación" y "televisión" han comenzado a aparecer unidos en muchas de las investigaciones académicas. Algo de gran relevancia, teniendo en cuenta que la programación televisiva propone modelos de realidad donde, en función de esas representaciones, los propios televidentes se perciben como seres con un género determinado (Storey, 2001). 
En este sentido, los estudios de género se conformarían como un campo de estudios específicos en el terreno de los Estudios Culturales, al coincidir con éstos en el planteamiento de algunas cuestiones como la de hegemonía frente a formas de resistencia, como se podrá apreciar en el planteamiento de este estudio.

No obstante, y a pesar de sus avances, los estudios de género fueron encontrando numerosas trabas en su desarrollo. Una de ellas fue la ridiculización de sus pretensiones y de su propia configuración como movimiento.

\subsection{Hipótesis y objetivos de la investigación}

Según Larumbe (2004: 331 y 332), los movimientos feministas encontraron numerosas trabas para su desarrollo durante la Transición, lo que produjo una serie de sentimientos negativos por parte de la población hacia este colectivo, basados en dos principios: la denegación y la psicologización.

La denegación consiste en no conceder la menor verosimilitud a los postulados defendidos por la minoría, reafirmando que las únicas ideas correctas son las de la mayoría. Para ello se utilizan argumentaciones vacías muy frecuentemente expresadas en el lenguaje coloquial: "es absurdo", "va en contra del sentido común", etc.

El otro fenómeno de resistencia que resulta mucho más eficaz es la psicologización. Es un mecanismo que se centra en juicios sobre la misma minoría, apoyándose en la percepción social que de ella se tiene, lo que supone valoraciones en sentido negativo, minusvalorándola y desacreditándola. Se sirve de estereotipos, juicios de valor, etc. Por ejemplo, afirmar que alguien es un "anormal", "loco" o "traidor"...

La denegación, en el caso del feminismo, es el antifeminismo, tan antiguo como los movimientos por la emancipación de la mujer; y la misoginia, anterior en sus manifestaciones a éste. Ambos han servido para despreciar a las mujeres por el mero hecho de serlo y han utilizado la psicologización para connotar peyorativamente a aquellas que han intentado luchar por cambiar esa situación. Todas estas estrategias han sido aplicadas en el análisis de las series analizadas, como se verá posteriormente.

Según Larumbe (2006:336) tanto la misoginia como el antifeminismo, sirviéndose de procedimientos muy distintos como el argumento de autoridad o la ironía (entre otros) han sido, a lo largo de los años, modos de denegación de las pretensiones feministas. Con la burla, se devaluaba tanto la pretensión como el estilo de la minoría, consiguiendo un mayor impacto, pues la minoría comenzaba a ser reconocida por la población desde ese estereotipo desprestigiado.

El antifeminismo también ensayó otras fórmulas más sutiles como la de "ponderar el importante avance experimentado por la mujer en los últimos lustros y lo mucho que había mejorado su situación respecto al pasado" (Larumbe, 2008: 340). Este argumento afirmaba que la mujer había sido o era víctima de una situación injusta pero que ya no lo era o que iba a dejarlo de ser muy pronto. 
Se puede afirmar, por tanto, que el antifeminismo ha ido construyendo el estereotipo de la mujer "feminista" a través de la psicologización negativa. Algunas de las estrategias frecuentes han sido la utilización del sarcasmo, por ejemplo mostrando a la mujer con características masculinas o mejor dicho, un modelo de mujer "hombruna", ocupada en tareas impropias de su sexo y sometiendo al varón a toda clase de humillaciones y violencias. Es decir, a través del modelo de una mujer maltratadora y dominante, que ha pasado de víctima a verdugo.

El antifeminismo contemporáneo ha completado ese arquetipo reactualizando algunos elementos como el histerismo agresivo de las feministas, al que ha añadido un rasgo muy actual, que es su sexualización. La relación feminismo/lesbianismo ha sido uno de los clichés más utilizados para fraguar el estereotipo moderno. Este estereotipo ha sido muy recurrente en los chistes, en comentarios populares, en la prensa y medios de comunicación como la televisión, estando muy interiorizado hoy en día.

Con el fin de analizar esa construcción que de la mujer y de los movimientos feministas españoles en la Transición se han hecho en la televisión actual, se han seleccionado dos series emitidas con ocho años de diferencia en canales generalistas, uno de entidad pública y otro privado, muy representativas para el estudio de todos estos factores que se han planteado: Cuéntame cómo pasó (TVE-1, 2001) y La chica de ayer (Antena 3, 2009).

Considerando el total de ficciones históricas emitidas desde el año 2001, las ficciones ubicadas en este período han sido muy poco numerosas. Entre ellas, se pueden citar Los 80 (Telecinco, 2004), producida por BocaBoca, ubicada en el año 1981, unos meses antes del Golpe de Estado, de la que se emitieron tan sólo seis capítulos por su falta de audiencia. Los 80 mostraba una imagen de España a través del punto de vista de dos familias, pertenecientes a diferentes clases sociales. No obstante, la serie se centró principalmente en la movida y el surgimiento de distintos grupos musicales. Aunque no era el objetivo de la ficción, en algunos momentos se trataron aspectos relacionados con la evolución de la mujer, como sucedió en el capítulo 3: "El divorcio que viene".

Otra de las series ubicadas en este período histórico fue Generación D.F. (Antena 3 , 2008), producida por Boomerang TV, que tenía un formato de tira semanal de 15-20 minutos. Contaba las anécdotas de la generación de jóvenes españoles nacidos en los 70, educados en libertad y que en ese momento rondaban la treintena.

Otra miniserie de dos capítulos que se centró principalmente en temas políticos fue 23-F, Historia de una traición (Antena 3, 2009), producida por Antena 3 Films y Cuarzo, que revelaba aspectos muy poco conocidos del intento de Golpe de Estado del 81. Lo mismo sucedía con 23 F: El día más difícil del Rey (TVE-1, 2009), producida por Alea Docs \& Films en coproducción con TVE y TV3, que recreaba uno de los episodios más delicados de nuestra historia reciente, centrándose en la figura del Rey como artífice de la democracia. 
En la misma línea fue Adolfo Suárez, el presidente (Antena 3, 2010) de Europroducciones, telefilme sobre la vida del ex presidente que constaba de dos partes de 70 minutos. La primera narraba su juventud y su carrera política hasta que era investido presidente. La segunda, retrataba sus años de gobierno hasta el golpe del 23-F.

Los Quien (Antena 3, 2011), de Producciones Aparte, fue una sitcom de 50 minutos de duración, protagonizada por Javier Cámara y María Pujalte, que narraba el día a día de la primera pareja española que se acogió a la ley del divorcio. La serie hablaba de conflictos muy reconocibles y universales que se iban repitiendo a través del tiempo, pero tratados con la ironía, el humor ácido y la perspectiva que daban los treinta años que han pasado desde entonces.

En otra línea también se ubicó la miniserie Historias robadas (Antena 3, 2012), producida por Antena 3 Films y BocaBoca, inspirada en casos reales de hermanos separados al nacer, en los años 70 y 80 , cuando algunas clínicas de maternidad repartidas por todo el país fueron acusadas de organizar lucrativos negocios de tráfico de niños.

Cuéntame cómo pasó y La chica de ayer son, de todas ellas, las dos ficciones que más se han centrado en los primeros años de Transición y que han resultado más pertinentes, por su enfoque directo, para analizar la representación de la mujer en esa época.

La primera de ellas, Cuéntame cómo pasó (TVE-1, 2001), de Grupo Ganga Producciones, fue una de las series que revolucionaron el panorama televisivo. Primero, porque se trató de una revisión histórica y nostálgica del pasado, pero también porque mostraba un modelo de vida diferente al actual, reconocible por los telespectadores, y además iba dirigido a todos los miembros de la familia. Por ello, podía clasificarse entre ficción histórica y serie familiar.

La longevidad de la serie se explica por el gran éxito obtenido desde el comienzo, lo que permitió su emisión durante doce años. En sus orígenes, la serie de TVE se programó en una franja estable, los jueves en horario de prime-time, y su público estuvo integrado por una leve mayoría de mujeres y con una media de edad dominante superior a los cuarenta y cinco años.

El análisis realizado se ha centrado en los capítulos que han desarrollado argumentalmente la muerte de Franco y la posterior Transición democrática. Concretamente, en la temporada 9, emitida en 2007 y 2008 y ubicada en el año 1975 (capítulos 140-161); la temporada 10, emitida en 2008 y ubicada en 1976 (capítulos 162-180), la temporada 11, emitida en 2009 y desarrollada en el año 1977 (capítulos 181-197); la temporada 12, emitida en 2010 y ambientada en el año 1978 (capítulos 198-215); y finalmente, la temporada 13, emitida en 2011-2012 y ambientada en 1979 y 1980 (capítulos 216-233), cerrando la muestra con el especial dedicado al Día de la Mujer (capítulo 229). A lo largo de todas estas emisiones, el personaje de Mercedes ha servido como hilo conductor para el desarrollo de muchas de las tramas relacionadas con la evolución de la mujer. 
A partir del éxito de series como Cuéntame cómo pasó y otras miniseries como las mencionadas, cadenas privadas como Antena 3 se subieron al carro de la producción de ficciones históricas, y una de ellas fue la adaptación española de la serie Life on Mars ${ }^{4}$, producida por Ida y Vuelta y titulada La chica de ayer (Antena 3, 2009).

La serie de Antena 3 narraba la historia de un policía de 2009 que viajaba en el tiempo hasta 1977. El choque del personaje protagonista, Samuel Santos con la España de la Transición, permitía a los espectadores descubrir cómo era entonces el país, siguiendo la tendencia de las series históricas al estilo de la ya mencionada Cuéntame cómo pasó (TVE-1, 2001). También desarrollaba la búsqueda por parte del protagonista de sus raíces y de sus seres queridos y la lucha de un hombre atrapado en el tiempo y su relación amorosa con una mujer, Ana, que vivía en 1977.

En la serie inglesa, Sam Tyler viajaba hasta 1973, pero en España se optó por llevar a Samuel Santos al 1977, en plena Transición, pues daba más juego, ya que 1973 en España era una época mucho más oscura, que además no permitía introducir elementos de comedia. Por otro lado, algunas tramas nuevas como el feminismo o la homosexualidad no se podrían haber explotado en el tardofranquismo.

El hecho de que la sociedad española hubiese cambiado tan drásticamente en sólo tres años, le daba un gran juego a los guionistas, en ese viaje al pasado de un personaje que sabía lo que estaba por venir. En este sentido, la serie española ofrecía una serie de novedades que los guionistas de Ida y vuelta supieron aprovechar, como la situación de las mujeres en la España de los setenta, en la que no existía ni el divorcio y la desigualdad estaba a la orden del día. Sin embargo, estos contrastes tan sólo convencieron a 2,7 millones de espectadores, unas cifras muy dignas para una serie diferente e innovadora, pero no suficientes para que La chica de ayer siguiera en antena.

\section{4. "Yo también soy adúltera": feminismo, mujer y sexualidad en la Transición}

A finales de 1978, las mujeres realizaron una intensa práctica social en la reivindicación de sus derechos. Las respuestas colectivas que generaron en la calle en diversas movilizaciones les confirieron una clara percepción de pertenencia a una comunidad cultural y política que reclamaba derechos y responsabilidades. Uno de estos escenarios fue la campaña en torno a la abolición del delito del adulterio:

El artículo 449 del Código Penal castigaba con pena de prisión menor, hasta seis años, a cualquier mujer por el hecho de yacer con un hombre que no fuera su marido. Por el contrario, el hombre sólo se consideraba adúltero en el caso de que tuviese manceba dentro de la casa conyugal o notoriamente fuera de ella" (Nash, 2009: 82).

Al no existir divorcio, si la mujer era denunciada como adúltera, perdía todos los derechos de la custodia de su hijo. Hubo muchas movilizaciones a raíz de la aplicación de esta ley discriminatoria al caso de María Ángeles Muñoz López, a la que habían 
ordenado la retirada de la custodia de su hija. A pesar de estar separada de hecho y de mantener ella sola a su hija, sin manutención alguna del padre, fue acusada por adulterio al quedarse embarazada de otro hombre, reclamando el marido la custodia de su hija. El juez se la concedió a la abuela paterna. La organización feminista Asociació Catalana de la Dona (ACD) organizó una campaña mediática y de movilización en su apoyo cuando el 12 de noviembre María Ángeles Muñoz se negó a cumplir la orden judicial de entregar a su hija de seis años en el juzgado, pidiendo una suspensión en la actuación judicial y el reconocimiento de la custodia de su hija.

A lo largo de las semanas siguientes hubo muchas manifestaciones que lograron atraer la atención y el apoyo a sus demandas. Muchos grupos feministas se presentaron en los juzgados con camisetas como "No a las leyes que discriminan a la mujer", "No a la pena por adulterio", "No somos propiedad del marido" o "Yo también soy adúltera". Como acto masivo de desobediencia civil y de identificación de las mujeres con María Ángeles Muñoz, se consiguió en octubre de 1977 firmar un acuerdo donde se retiraba la denuncia contra ella y la salvaguardia y custodia de su hija, pero la ley que consideraba el adulterio como delito no se derogó hasta el 26 de marzo de 1978.

A partir de esta acción colectiva, como añade Mary Nash (2009: 83), "se creó una dinámica de pertenencia y de identidad feminista común". En sus formas organizativas, siguieron los modelos norteamericano y europeo. Lo común fue optar por formas asamblearias y abiertas. La mayor parte de las mujeres que acudían, influidas por alguna compañera de trabajo o por docentes, buscaban respuesta a conflictos personales, familiares; es decir, orientación para resolver algún problema concreto. Muchas de estas asociaciones adoptaron la doble militancia.

Sin embargo, la ley del divorcio tardaría años en llegar, si bien algunas asociaciones ya empezaron a plantear y a exigir este derecho desde el año 1976 bajo eslóganes como "No más separaciones: "divorcio de una vez"; o "Por una ley justa y no discriminatoria del divorcio". Sin embargo, esta ley no se materializaría hasta el año 1983, pues no fue una de las prioridades para ninguno de los partidos políticos en el poder.

En el capítulo 170 de Cuéntame cómo pasó, "La mujer del César", ambientado en octubre de 1976, se mostraba el juicio comentado anteriormente, que marcó un antes y un después en el planteamiento del movimiento feminista en España. En este capítulo, Mercedes, animada por sus compañeras de Universidad, firmaba un manifiesto para apoyar a una mujer acusada de supuesto adulterio, y castigada con una multa de 150 mil pesetas, la retirada de la custodia de sus hijos y posible pena de cárcel. Lo que no sabía es que ese manifiesto iba a salir publicado al día siguiente en Diario 16 bajo el lema "Yo también soy adúltera".

La secuencia empezaba con un cartel en la pared donde se indicaba "por la libertad de la mujer", y alguien leía un escrito de protesta por el caso de María Ángeles Muñoz, previamente comentado. Este escrito, dirigido al Ministerio y a otras asociaciones feministas, reclamaba que no se podía juzgar por lo penal un caso que estaba en el terreno de lo privado. Terminaba: "todas unidas por la liberación de la mujer" (en las paredes, podían verse carteles con el eslogan "afíliate"). 
La siguiente escena mostraba a Antonio Alcántara y a otro compañero de trabajo, que eran cómplices de la infidelidad de uno de ellos, casado, mientras hablaban de sus respectivas mujeres como seres sumisos y dependientes.

En contraposición a estas perfectas esposas están esas "locas que me hacen muchas gracia" - según palabras del personaje de Imanol Arias en la serie. Éste teme que su Mercedes se convierta en "una de esas que no se depilan las piernas ni para ir al médico" (de nuevo atributos despectivos y negativos hacia el colectivo), porque critica el doble rasero al juzgar la infidelidad en un matrimonio: la culpa es siempre de las mujeres. Si un hombre pone los cuernos es porque le liaba una "buscona" y si los ponían las mujeres, entonces eran una adúlteras. Pero aunque Mercedes defienda las ideas de las feministas, no se identifica con ellas. "Ni soy feminista, ni quiero serlo - reconoce a su marido -. Solo quiero que se trate a las mujeres igual que a los hombres". Dicha afirmación es una contradicción en sí misma, dado que el feminismo es precisamente eso, la lucha por la igualdad de trato entre hombres y mujeres.

En cualquier caso, la serie, sin profundizar demasiado en estas cuestiones, acababa optando por una salida políticamente correcta cuando Antonio reconocía al final del capítulo que las mujeres "eran más listas que el hambre" y que todavía no lo sabían, "por eso sólo piden igualdad - afirmaba el personaje de Imanol Arias-, pero cuando lo sepan, la que van a liar". Sin duda, se trata de una frase articulada desde un tiempo presente, desde donde se revisa la evolución de la mujer, sabiendo de antemano adónde ha conducido esa situación previa y dejando en buen lugar al género masculino, con una visión integradora.

\section{1 "En mi cama mando yo": ¿destape o libertad sexual?}

"En mi cama mando yo" - gritaba una grupo de feministas frente a una sala de fiestas para hombres en la primera secuencia del capítulo 5 de La chica de ayer. Esta frase resumía las reivindicaciones del movimiento feminista español, entre las que se encontraban los derechos a la libre disposición del propio cuerpo - acceso a los anticonceptivos, despenalización del aborto -, así como una denuncia de la ideología patriarcal basada en la familia y en el mito de la maternidad (Larumbe, 2005: 12).

En aquellos años, el sexo se concebía como fuente de reproducción y no como fuente de placer: era pecado. Para las mujeres, la necesidad de satisfacer al hombre estaba por encima de la propia necesidad vital y sexual. Es por ello que muchas jóvenes de aquellos años, como las que aparecen en series como La chica de ayer o Cuéntame cómo pasó, empiezan a reivindicar una nueva sexualidad: ser más activas en el sexo e incluso nuevas formas de sexualidad como el lesbianismo. "Yo soy una mujer moderna - le reconoce la madre de Samuel a su hijo -. He visto muchas películas verdes de esas. Además, se aprende mucho" (Capítulo 6).

Pero no todas las mujeres de los setenta habían visto "películas verdes de esas", y para ellas, hablar de sexo era un gran tabú. Esta progresiva liberación de la mujer en materia de sexo se aprecia en las diferentes temporadas de Cuéntame cómo pasó. Mientras que en la primera temporada Mercedes se escandaliza porque su hija Inés 
usa píldoras anticonceptivas, y en el capítulo 99, todo el barrio de San Genaro se entera de la deshonra de Paquita que se ha acostado con su novio Quique, en las últimas temporadas, llegando a los años de la Transición, las mujeres se desinhiben en materia sexual. Se hace patente la diferencia generacional: mujeres como Josefina que en toda su vida sólo habían visto en cueros a su marido, y otras como François, Paquita $^{5}$ o Inés, que mantienen relaciones sexuales fuera del matrimonio.

Como narra la voz en off del Carlitos adulto de Cuéntame, "en aquella época la educación sexual era como los OVNIS, todo el mundo hablaba de ello, pero nadie sabía nada de nada" (Capítulo 229). A través del personaje del joven Carlitos se trata el tema del descubrimiento del sexo en los años de la Transición. Se aprecia la diferencia entre la concepción de las relaciones sexuales a finales de los sesenta, cuando su hermana Inés empieza a usar métodos anticonceptivos, y a finales de los setenta, cuando el joven Carlos mantiene relaciones con sus diferentes novias. En el primer capítulo de la serie, los anticonceptivos, eran para muchos "casi un tabú y para otros un pecado de los gordos", mientras que en las últimas temporadas, reflejo de los cambios sociales registrados en la España de la Transición, eran la normalidad.

Estos tabúes están muy relacionados con la moral católica aprehendida: las series reflejan una sociedad que se reprime en materia de sexualidad. Es una sociedad que va los sábados a ver Gilda y los domingos a misa para confesarse. Para las mujeres de La chica de ayer o Cuéntame, ver a hombres streapers que se quedan en cueros mientras las mujeres les meten un billete en la ropa interior, no es muy habitual. Sin embargo, para hombres como Gallardo ${ }^{6}$ y el resto de los policías, ir a salas de fiestas donde las mujeres no sólo se desnudan, sino que después del espectáculo se prostituyen, es el pan nuestro de cada día. Es más, la sociedad no veía con malos ojos a los hombres - incluso casados - que aplacaban su libido con prostitutas. Sin embargo, como muestra la serie de Antena 3 analizada, estas mujeres son tratadas con desprecio, además de condenadas socialmente, incluso tan sólo por ser bailarinas de una sala de fiestas.

En los últimos años del franquismo, con el llamado destape ${ }^{7}$, se observa una crisis de la moral católica y de la institución del matrimonio. Sin embargo, el destape seguía representando un modelo de sexualidad machista en el que las mujeres eran objetos sexuales. Como se señala en La chica de ayer, la libertad que llegó en la Transición había dado mayor libertad a las salas de fiestas en cuestión sexual, pero siempre dentro de un modelo de sexualidad machista en el que se buscaba el placer masculino. El sexo parecía ser un privilegio exclusivo de los hombres. Ellas no pueden tener deseo carnal, sólo pueden ser objetos sexuales.

En numerosas secuencias de La chica de ayer los personajes masculinos manifiestan verbalmente su deseo hacia las mujeres, a las que tan sólo ven como un objeto. Los comentarios con referencias sexuales hacia sus compañeras de trabajo o hacia las mujeres que acuden a la comisaría se suceden uno tras otro. Para ellos, las mujeres van provocando, "pintadas como puertas", "poniéndoles cachondos" y "alegrándoles la vista un rato". No tratan de la misma manera a un hombre que entra en la comisaria 
que a una mujer. Con ellas flirtean, les miran el escote cuando llegan y el trasero cuando se van.

Pero de la boca de estos policías no sólo salen piropos hacia las mujeres - algunos de ellos groseros -, sino también continuas referencias a su virilidad. Hacen uso de un lenguaje machista y sexista para mostrar que son muy machos. El tamaño de su miembro y las continuas referencias a sus genitales son el modo que tienen personajes como Gallardo de reafirmar su virilidad y demostrar que son tipos duros.

Frente a estos machos, están "las nenazas". Todo aquel que no se comporta como Gallardo es porque es un "pichafloja". Este tipo de insultos se mezclan con expresiones y bromas de carácter sexista en las que se denigra a la mujer: si un hombre no "se encuentra el pito" es porque es una "señorita". Los tipos duros como estos policías se pasan el día en el bar mientras las mujeres están en casa pegadas a la lavadora ${ }^{8}$. Beben alcohol para demostrar que tienen pelos en el pecho. Ellos beben, fuman y fanfarronean, mientras ellas toman infusiones y cotillean. Pero estos rígidos esquemas de identidad de género comienzan a romperse en estos años. Los hombres empiezan a dejarse el pelo largo, y las mujeres como Ana llevan pantalones y fuman. Como señala María Luisa Jiménez (2008: 1), el consumo de tabaco hasta hace pocas décadas ha sido considerado como una práctica propia de los hombres 9 . En España, en los últimos años del franquismo, aumenta el consumo de tabaco entre las mujeres como símbolo de modernidad: fumar un cigarrillo rompe los parámetros tradicionales de la feminidad y representa una mayor autonomía por parte de la mujer, como vestir pantalones, llevar el pelo corto o conducir un coche (Jiménez, 2008: 2-3).

El tema de la igualdad de género se trata en La chica de ayer teniendo siempre en cuenta la actualidad de la serie. El espectador entra en el juego de dobles lecturas que se establece gracias a la llegada de un viajero del tiempo como Samuel. "El futuro es mejor para la mayor parte de la gente - dice a una de las mujeres de la serie-, sobre todo para ti". Samuel, que conoce el presente, sabe que la situación de las mujeres es mejor en la actualidad. La idea sobre el presente que transmite al espectador es positiva: frente a la opinión común de que cualquier tiempo pasado fue mejor, la serie subraya continuamente todo lo contrario. Es por ello que la sensación final para el público es de consenso: España ha progresado mucho desde los años setenta hasta ahora y es una gran suerte vivir en el tiempo actual, donde parece que toda la sociedad es tolerante como Samuel; donde parece no existir el machismo; donde la mujer ya no tiene que manifestarse gritando "en mi cama mando yo".

\section{2 "Nosotras parimos, nosotras decidimos". Mujer y movimientos políticos}

La lucha por la despenalización del aborto fue la más larga y conflictiva del feminismo en España. Bajo el lema "Anticonceptivos para no abortar, aborto para no morir", se demandaba una sexualidad libre y autónoma que nunca fue prioridad en el panorama político español. Como asegura Larumbe (2008:178) "Esta cuestión siempre fue central para el movimiento feminista y secundaria para todos los partidos 
(...)". Pero poco a poco comenzó a ser considerado también de importancia por los sectores progresistas.

El tema de la libertad de la mujer para elegir sobre su propio cuerpo, fue planteado en el capítulo 180 de Cuéntame cómo pasó, "Año nuevo, vida nueva". En él se mostraban imágenes de archivo de manifestaciones de grupos feministas con la pancarta: "Nosotras parimos, nosotras decidimos", así como distintas opiniones de las mujeres alrededor de los hombres, así como sobre la castidad y las relaciones antes o después del matrimonio, tanto a favor como en contra, según edad y generación.

Hasta la temporada 12, capítulos 198-215, no se volvía a mencionar el tema de la mujer. Estos capítulos se centraban en la evolución de las libertades y de la sociedad española con la llegada de la Transición. Concretamente, en el capítulo 202, que transcurría en septiembre de 1978, Mercedes participaba, convencida por Antonio que había comenzado a desarrollar su carrera política, en las Primeras Jornadas de la Condición Femenina. En una escena, Mercedes daba una ponencia y decía que, gracias a la Constitución, se reconocía por primera vez la igualdad entre hombres y mujeres y que no era el momento de poner zancadillas al proceso, sino de apoyarlo. $\mathrm{Su}$ marido asistía a la ponencia atendía orgulloso. Una pancarta tras ella indica: "Mujeres y trabajo remunerado". Las otras dos ponentes feministas, le reprochaban que debido a la situación patriarcal imperante, en la redacción del texto no había intervenido ninguna mujer. Con lo cual, confiar en lo que pudiese salir de ahí demostraba un poco de ingenuidad. Mercedes se defendía añadiendo que, además de por su trabajo, por lo que había luchado toda su vida había sido por su familia, y que si eso significaba ser una ingenua, que lo entonces lo era. Su discurso finalizaba diciendo que prefería confiar en el acuerdo y que si ellas lo llama ingenuidad, para ella es esperanza. Todos aplaudían.

Este breve discurso que cerraba el capítulo, ponía de manifiesto ese matiz unificador de la serie que tiene que ver con la corrección política y con un espíritu de consenso, que es objeto de debate en la actualidad.

\section{Conclusiones}

Una vez realizado el análisis de las dos series señaladas se puede observar una correspondencia desigual entre el papel activo en la Transición por parte de las mujeres españolas que los Estudios Feministas reclaman y la representación de los movimientos feministas presentada por las series de ficción histórica ambientadas en este periodo. En este tipo de producciones se invisibiliza la aportación de las españolas en este proceso de cambio y en el desarrollo de la democracia.

Las dos series reconstruyen de forma bastante fiel el contexto histórico y social, y las principales trabas en la evolución de la mujer en la sociedad española, con el fin de conectar con las telespectadoras actuales. En ambas series, se elogian los avan- 
ces en materia de género, sin embargo, se utilizan estereotipos despectivos hacia los colectivos feministas de forma recurrente para desmerecer los logros conseguidos.

Paradójicamente, estas series presentan una posición contradictoria cuando se refieren a los artífices de los cambios de la Transición. Los movimientos feministas aparecen como catalizadores, pero también como radicales, desfasados desde la perspectiva actual,y que se exceden en sus demandas. Las dos series coinciden en mostrar a las feministas como mujeres masculinizadas y agresivas que buscan la separación y no el consenso. Por tanto, se intuye que los logros conseguidos han sido gracias a los artífices de la Constitución, a sus impulsores (masculinos) y no a estas mujeres. Es decir, encierran un doble mensaje, por un lado progresista y por otro lado conservador. Progresista porque se postula del lado de las mujeres que manifiestan su disconformidad con la situación existente. Conservador, porque también las presenta como extremistas cuyo objetivo parece haber sido el de obstaculizar el proceso democrático.

Este doble discurso está muy relacionado con el momento actual de producción que determina las características de la representación de género al tener en cuenta factores sociales, culturales y políticos del contexto de recepción de la serie. Nada tienen que ver las mujeres de las películas de la movida con las de las series de prime time analizadas. La imagen de las feministas de las películas de los ochenta era mucho más política que en La chica de ayer o en Cuéntame cómo pasó. Su imagen actual está muy relacionada con la herencia social y política: mientras en las películas de los ochenta eran modernas y reinvindicativas, ahora parecen más unas locas, radicales y ridículas.

\section{Referencias bibliográficas}

ARÓSTEGUI, Julio. Retos de la memoria y trabajos de la historia. La memoria del pasado. Pasado y Memoria. Revista de Historia Contemporánea, 2004, pp.5-58. CABRERA PÉREZ, Luis Alberto. “1975-1983. La transición democrática”, en Mujer. Trabajo y Sociedad (1839-1983), Ediciones Sinsentido, Madrid, 2005.

CASCAJOSA VIRINO, "La chica de ayer: memoria y desmemoria televisivas de la Transición en España”, en Journal of Spanish Cultural Studies, 13:3, 260-275.

DE DIEGO GONZÁlEZ, Álvaro. Las mujeres de la transición. Congreso de los Diputados, Madrid, 2008.

DE LAURENTIS, Teresa. "Technologies of Gen-der. Essays on Theory" en Film and Fiction, Londres, Macmillan Press,1989, pp. 1-30.

DÍAZ, Susana. "La transición política como pretexto: 23-F. El día más difícil del Rey", en ZER Revista de Estudios de Comunicación, n³5. Bilbao: UPV/EHU, pp. 169-190.

GUARINOS, Virginia. "Mujer en constitución: la mujer española en el cine de la Transición” en Quaderns de cine , n 2, Cine i Transició (1975-1982), 2008, págs. 51-62. 
LARUMBE GORRAITZ, Ma Ángeles. "El feminismo en la transición democrática", en Rolde: Revista de cultura aragonesa, no 111-112, 2005, págs. 22-25.

LARUMBE GORRAITZ, Ma Ángeles. "El feminismo y la transición española”, en Laberintos $\mathrm{n}^{\circ}$ 6, 2005, Universidad de Zaragoza, pp.10.14.

LARUMBE GORRAITZ, M ${ }^{\mathrm{a}}$ Ángeles. Las que dijeron no: palabra y acción del feminismo en la Transición Universidad de Zaragoza, Zaragoza, 2004.

LARUMBE GORRAITZ, Ma Ángeles. Una inmensa minoría: influencia y feminismo en la Transición. Prensas Universitarias de Zaragoza, Zaragoza, pp. 139, 152.

NASH, Mary. "Mujeres en transición: ciudadanía femenina, legitimidad feminista y la creación de una nueva cultura política", en ORTEGA LÓPEZ, T. M.. Feminismos en la Transición. Mary Nash y Gemma Torres (Editoras). Grup de Recerca Consolidat i Genere Universitat de Barcelona y Sociedad Estatal de Conmemoraciones Culturales. Ministerio de Cultura, Barcelona, 2009.

PACHECO BARRIO, Manuel Antonio. "La reciente historia de España en la ficción televisiva", en Mediaciones Sociales, no 4, I semestre 2009, pp. 225-246.

RUBIALES TORREJÓN, Amparo. "Informe 8 de marzo de 2008" en 100 años trabajando por la igualdad, Secretaría para la Igualdad. Departamento Confederal de la Mujer. UGT, p.14.

RUEDA LAFFOND, José Carlos y CORONADO RUIZ, Carlota. La mirada televisiva: Ficción y representación histórica en España, vol. 83, Fragua Comunicación, Madrid, 2009.

RUEDA LAFFOND, José Carlos y GUERRA GÓMEZ, Amparo (2009): “Televisión y nostalgia. The Wonder Years y Cuéntame cómo pasó", en Revista Latina de Comunicación Social, 64, Universidad de La Laguna, La Laguna (Tenerife), pp. 396-409.

STOREY, John. Cultural Theory and Popular Culture. Londres, (PearsonIPrentlce Hall) 1 London et al, 2001.

\section{Notas}

1 Este trabajo se inscribe como resultado del proyecto de investigación "Memorias en segundo grado: Posmemoria de la Guerra Civil, el franquismo y la transición democrática en la España contemporánea". Ref. CSO2013-41594-P. Ministerio de Economía y Competitividad y dentro del Grupo de Investigación Complutense "Memoria y medios de comunicación” MEMCO (código 685).

2 Entre ellos, se pueden citar los siguientes: Estrada, Isabel: "Cuéntame cómo pasó o la revisión televisiva de la historia española reciente", en Hispanic Review, Vol. 72, No. 4 (otoño, 2004), pp. 547-564; Rueda Laffond, José Carlos y Guerra Gómez, María de los Desamparados (2009) Televisión y nostalgia. The Wonder Years y Cuéntame cómo pasó. Revista Latina de Comunicación Social (64), pp. 396-409; Díaz, Susana: "La transición política como pretexto: $23 F$. El día más difícil del Rey”, en Zer. Revista de Estudios de Comunicación, Vol. 18, nº 25, 2013, pp. 169-190; entre otros.

3 Existen estudios sobre la mujer en la ficción televisiva española actual, pero en ninguno se centran específicamente en las series sobre la Transición. Cabe citar los siguientes: Galán, Elena: “Construc- 
ción de género y ficción televisiva en España", en Comunicar : revista cientifica iberoamericana de comunicación y educación, Huelva, 2007, v. XV, n. 28, marzo, pp. 229-236; Tratamiento y representación de las mujeres en las teleseries emitidas por las cadenas de televisión de ámbito nacional, Instituto de la Mujer, Madrid, 2007, entre otros.

4 Serie británica que constó de dos temporadas, (con un total 8 episodios cada una).

5 En el personaje de Paquita se representa perfectamente el cambio en la mujer española de estos años: en las primeras temporadas, Paquita tiene una mentalidad propia del pueblo del que viene y poco a poco, gracias a su contacto con la ciudad, va cambiando. Esto se aprecia en sus comentarios: cuando se pone su primera minifalda afirma "van a decir que soy una cualquiera", preocupándose por el qué dirán; y sin embargo, capítulos más adelante, reivindica la sexualidad femenina con frases como "desde que se ha inventado la píldora, nos quedamos embarazadas cuando nos da la gana".

6 Gallardo es la contrafigura del personaje de Samuel en La chica de ayer. Representa la mentalidad y los valores de la sociedad española durante el franquismo.

7 En el capítulo 162 de la temporada 10 de Cuéntame cómo pasó - "Y llegó el destape"- se aborda el tema de la flexibilización de las normas sexuales represivas impuestas durante el franquismo.

8 Cuando el personaje de Rai hace referencia a su esposa, que se queja de él, dice "¡Coño, que le acabo de regalar una máquina de coser para su cumpleaños!” (Capítulo 6)

9 Esta carga masculina del cigarrillo, convirtió el tabaco en un símbolo social y político de la lucha feminista. (Jiménez Rodrigo, María Luisa: "Ilusiones de humo. Sentidos y sinsentidos del consumo femenino de cigarrillos", en El genio maligno. Revista de humanidades y ciencias sociales, $\mathrm{n}^{\circ} 2$, marzo 2008, pp. 1-18. 